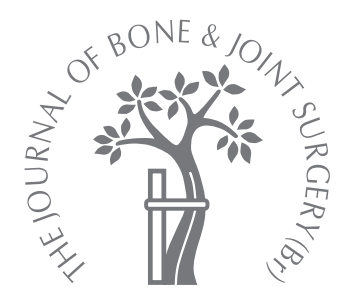

\title{
Isolated acetabular liner exchange compared with complete acetabular component revision in revision of primary uncemented acetabular components
}

\author{
A STUDY OF 1649 REVISIONS FROM THE NORWEGIAN \\ ARTHROPLASTY REGISTER
}
S. A. Lie,
G. Hallan,
O. Furnes,
L. I. Havelin,
L. B. Engesæter

From Haukeland

University Hospital,

Bergen, Norway

S. A. Lie, MSc, PhD, Research Fellow (Statistician)

Department of Health

University Research Bergen, N5015 Bergen, Norway

G. Hallan, MD, PhD,

Orthopaedic Surgeon

O. Furnes, MD, PhD,

Orthopaedic Surgeon

L. I. Havelin, MD, PhD,

Professor, Orthopaedic

Surgeon

L. B. Engesæter, MD, PhD

Professor, Orthopaedic

Surgeon

The Norwegian Arthroplasty

Register, Department of

Orthopaedic Surgery

Haukeland University Hospital,

Mollendalsbakken 11, N-5021

Bergen, Norway.

Correspondence should be sent to Mr S. A. Lie; e-mail:

Stein.Lie@unifob.uib.no

(C2007 British Editorial Society

of Bone and Joint Surgery

doi:10.1302/0301-620X.89B5.

$18623 \$ 2.00$

$J$ Bone Joint Surg $[\mathrm{Br}]$

2007;89-B:591-4.

Received 7 September 2006

Accepted 7 December 2006

We analysed the results of different strategies in the revision of primary uncemented acetabular components reported to the Norwegian Arthroplasty Register. The aim was to compare the risk of further acetabular revision after isolated liner exchange and complete component revision. The results of exchanging well-fixed components were also compared with those of exchanging loose acetabular components. The period studied was between September 1987 and April 2005. The following groups were compared: group 1, exchange of liner only in 318 hips; group 2, exchange of well-fixed components in 398; and group 3, exchange of loose components in 933 . We found that the risk of a further cup revision was lower after revision of well-fixed components (relative risk from a Cox model $(R R)=0.56$, $\mathbf{9 5} \%$ confidence interval $\mathbf{0 . 3 7} \%$ to $\mathbf{0 . 8 7} \%$ ) and loose components (RR $=\mathbf{0 . 5 6}, \mathbf{9 5} \%$ confidence interval $0.39 \%$ to $0.80 \%$ ), compared with exchange of the liner in isolation. The most frequent reason for a further acetabular revision was dislocation, accounting for 61 (28\%) of the re-revisions. Other reasons for further revision included pain in 27 (12\%), loosening in 24 $(11 \%)$ and infection in 20 (9\%). Re-revisions because of pain were less frequent when complete component (fixed or loose) revision was undertaken compared with isolated exchange of the liner (RR $=0.20$ (95\% confidence interval $0.06 \%$ to $0.65 \%$ ) and $\mathbf{R R}=\mathbf{0 . 1 0}$ (95\% confidence interval $0.03 \%$ to $0.30 \%)$, respectively). The risk of further acetabular revision for infection, however, did not differ between the groups.

In this study, exchange of the liner only had a higher risk of further cup revision than revision of the complete acetabular component. Our results suggest that the threshold for revising well-fixed components in the case of liner wear and osteolysis should be lowered.

In a recent study, we showed that in revision total hip replacement there were differences in the outcome between revision procedures undertaken with and without cement, and that the risk of further revision is greater in the absence of bone allograft reconstruction, ${ }^{1}$ especially for the femoral component. In the current study we focused exclusively on revisions of uncemented primary acetabular components.

Whether or not to revise a well-fixed and well-placed uncemented acetabular component is controversial. Some studies argue that leaving the well-fixed acetabular component unchanged at revision diminishes the probability of post-operative dislocation, ${ }^{2-4}$ whereas other reports claim the opposite..$^{5,6}$

The indications for revising a well-fixed component, apart from infection and malposi- tion, include gross osteolysis. Acetabular components with recognised poor performance or those that do not match the femoral component used may justify removal. Simple exchange to a new, identical liner that has been shown to have poor wear properties may be contraindicated. However, wear and moderate osteolysis in the presence of well-fixed and correctly orientated acetabular components is often treated by isolated exchange of the liner and femoral head, or combined with bone grafting to restore bone stock. ${ }^{7}$

We found no studies reporting whether leaving or revising the uncemented acetabular component affects the survival of the revision prostheses. In the present study, the results of isolated liner exchange were compared with those following complete revision of loose or fixed acetabular components. 
Table I. Descriptive statistics for the different categories of revisions

\begin{tabular}{|c|c|c|c|c|c|c|c|c|}
\hline $\begin{array}{l}\text { Component changed } \\
\text { at revision operation }\end{array}$ & Revisions & Females & $\begin{array}{l}\text { Mean age } \\
\text { (yrs) at revi- } \\
\text { sion (SD) }\end{array}$ & Right hip & Primary $O A^{*}$ & $\begin{array}{l}\mathrm{HA}^{\dagger} \text { coated cups } \\
\text { with smooth } \\
\text { surface }\end{array}$ & $\begin{array}{l}\text { Mean time } \\
\text { interval (yrs) } \\
\text { from primary to } \\
\text { revision } \\
\text { operation (SD) }\end{array}$ & $\begin{array}{l}\text { Bone transplant or impac- } \\
\text { tion, in acetabulum at revi- } \\
\text { sion }\end{array}$ \\
\hline Liner & 318 & 230 & $58.4(13.0)$ & 165 & 136 & 191 & $7.3(3.6)$ & 45 \\
\hline A fixed cup & 398 & 266 & $59.5(12.6)$ & 192 & 181 & 119 & $6.8(4.0)$ & 174 \\
\hline A loose cup & 933 & 606 & $61.5(12.4)$ & 506 & 411 & 323 & $8.0(3.3)$ & 564 \\
\hline Total & 1649 & 1102 & $60.4(12.6)$ & 863 & 728 & 633 & $7.5(3.6)$ & 783 \\
\hline
\end{tabular}

* OA, osteoarthritis

${ }^{\dagger} \mathrm{HA}$, hydroxyapatite

Table II. Revisions, re-revisions, and reasons for re-revision

\begin{tabular}{|c|c|c|c|c|c|c|c|}
\hline \multirow{2}{*}{$\begin{array}{l}\text { Component changed } \\
\text { at revision operation }\end{array}$} & \multirow[b]{2}{*}{ Revisions } & \multirow[b]{2}{*}{ All cup and liner re-revisions } & \multicolumn{5}{|c|}{ Reasons for re-revision } \\
\hline & & & Loose acetabulum & Dislocation & Pain & Infection & Major wear of cup \\
\hline Liner & 318 & 52 & 4 & 17 & 13 & 5 & 7 \\
\hline A fixed cup & 398 & 47 & 3 & 19 & 6 & 4 & 4 \\
\hline A loose cup & 933 & 119 & 17 & 25 & 8 & 11 & 7 \\
\hline Total & 1649 & 218 & 24 & 61 & 27 & 20 & 18 \\
\hline
\end{tabular}

Table III. Cox-regression analyses, for cause specific risk of re-revision, after categories of revisions

\begin{tabular}{|c|c|c|c|c|c|c|c|c|c|c|c|c|}
\hline \multirow{2}{*}{$\begin{array}{l}\text { Component } \\
\text { changed } \\
\text { at revision }\end{array}$} & \multicolumn{2}{|c|}{ All cup re-revisions } & \multicolumn{2}{|c|}{ Loose acetabulum } & \multicolumn{2}{|l|}{ Dislocation } & \multicolumn{2}{|l|}{ Pain } & \multicolumn{2}{|l|}{ Infection } & \multicolumn{2}{|c|}{ Major wear of cup } \\
\hline & $\mathbf{R R}^{*}(95 \% \mathrm{Cl})$ & p-value & $\mathrm{RR}^{*}(95 \% \mathrm{Cl})$ & p-value & $\mathrm{RR}^{*}(95 \% \mathrm{Cl})$ & p-value & $\mathbf{R R}^{*}(95 \% \mathrm{Cl})$ & p-value & $\mathrm{RR}^{*}(95 \% \mathrm{Cl})$ & p-value & $\mathrm{RR}^{*}(95 \% \mathrm{Cl})$ & p-value \\
\hline Liner & 1 & $t$ & 1 & $t$ & 1 & $t$ & 1 & $t$ & 1 & $t$ & 1 & $t$ \\
\hline A fixed cup & $\begin{array}{l}0.56 \\
(0.37 \text { to } 0.87)\end{array}$ & 0.009 & $\begin{array}{l}0.27 \\
\text { (0051 to } 1.38 \text { ) }\end{array}$ & 0.12 & $\begin{array}{l}0.88 \\
(0.43 \text { to } 1.81)\end{array}$ & 0.73 & $\begin{array}{l}0.20 \\
(0.06 \text { to } 0.65)\end{array}$ & 0.007 & $\begin{array}{l}0.62 \\
(0.15 \text { to } 2.56)\end{array}$ & 0.51 & $\begin{array}{l}0.47 \\
(0.13 \text { to } 1.70)\end{array}$ & 0.25 \\
\hline A loose cup & $\begin{array}{l}0.56 \\
(0.39 \text { to } 0.80)\end{array}$ & 0.001 & $\begin{array}{l}0.59 \\
\text { (0.17 to } 2.06)\end{array}$ & 0.41 & $\begin{array}{l}0.45 \\
(0.23 \text { to } 0.88)\end{array}$ & 0.019 & $\begin{array}{l}0.10 \\
(0.03 \text { to } 0.30)\end{array}$ & $<0.001$ & $\begin{array}{l}0.67 \\
\text { (0.21 to } 2.13 \text { ) }\end{array}$ & 0.50 & $\begin{array}{l}0.26 \\
(0.09 \text { to } 0.80)\end{array}$ & 0.018 \\
\hline Total & & $0.005 \ddagger$ & & $0.28 \ddagger$ & & $0.023 \ddagger$ & & $<0.001 \ddagger$ & & $0.76 \ddagger$ & & $0.062 \ddagger$ \\
\hline
\end{tabular}

*, adjusted for age, gender, and cemented acetabulum at revision

$t$, reference category to which the other categories are compared

$\ddagger$, test for homogeneity

\section{Patients and Methods}

This study was based on revision of primary uncemented acetabular components reported to the Norwegian Arthroplasty Register between September 1987 and April 2005. Approximately $90 \%$ of all hip replacements, including revisions, are reported to the Register. ${ }^{8}$ The function of the register has been described. ${ }^{9}$ During the period of the study, 16952 primary uncemented acetabular components of 60 different types were implanted in Norway, and 1649 revisions of these implants were reported. We recorded the time from the first revision of the whole component or exchange of liner, to the subsequent acetabular revision. Sub-analyses with cause-specific end-points, such as aseptic cup loosening, dislocation, pain, infection, and major wear of the liner were undertaken. For the cause-specific analyses, the time of the observation was censored if the prostheses were rerevised for causes other than those studied. A specific subanalysis was performed for smooth-surfaced primary acetabular components with hydroxyapatite (HA) coating, as these implants have been shown to have poor results in the register. ${ }^{10}$ Sub-analysis of all the other acetabular components was also undertaken.
Survival time was measured from the revision, and not from the primary operation. The hips were divided into three study groups according to whether the liner only (group 1), a well-fixed component (group 2) or a loose component (group 3) was revised. In order to investigate the influence of revision of the femoral component the two latter groups were further divided into subgroups, with and without concomitant revision of the femoral component. Statistical methods. Based on the Kaplan-Meier survival analysis, the probability of failure (one minus survival) has been presented. In order to estimate differences in risk for re-revision between the three groups, Cox regression models adjusted for age, gender, and cemented or uncemented acetabular revisions, were used to produce the relative risk (RR) of failure and the $95 \%$ confidence interval (CI). The level of significance applied was $\mathrm{p} \leq 0.05$. Other confounding factors were not considered because of the fairly homogeneous subset used in this study.

\section{Results}

The mean age at revision was 59.2 years (14 to 88 ) for males and 61.1 years (17 to 91) for females. There were 


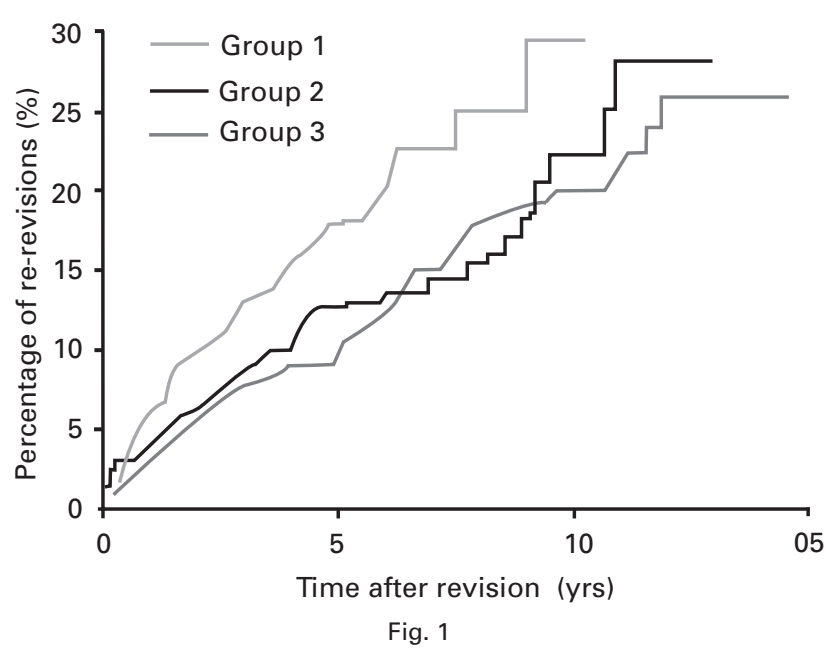

Failure curves (one minus Kaplan-Meier survival), for time to re-revision of the acetabular component for any reasons, by categories of revision, isolated liner exchange (group 1); complete revision of a wellfixed acetabular component (group 2) and complete revision of a loose acetabular component (group 3).

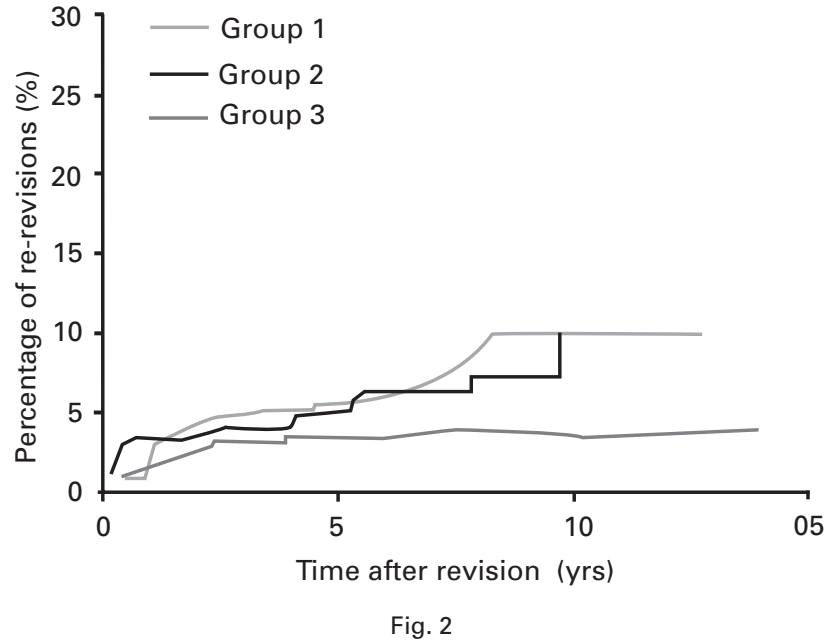

Failure curves (one minus Kaplan-Meier survival), for time to re-revision of the acetabular component due to dislocation, by categories of revision, isolated liner exchange (group 1); complete revision of a wellfixed acetabular component (group 2) and complete revision of a loose acetabular component (group 3).
547 males (33.2\%) and 1102 females (66.8\%). The distribution of other variables is presented in Table I.

The most frequent reason for a further revision was dislocation, accounting for $61(28 \%)$ of the re-revisions. Pain in $27(12 \%)$, loosening of the acetabular component in 24 $(11 \%)$, infection in $20(9 \%)$, and major wear in 18 $(8 \%)$,were other relatively frequent causes of re-revision (Table II).

In the Cox regression model, isolated exchange of the liner (group 1) was set as the reference, against which the other two groups were compared. We found that for group 2 (exchange of well-fixed acetabular components), the risk of re-revision was significantly lower than for group 1 (RR $=0.56,95 \%$ CI $0.37 \%$ to $0.87 \%)$. Similarly, group 3 (exchange of loose acetabular components) had a statistically significant lower risk for re-revision than revisions of the liner only ( $\mathrm{RR}=0.56,95 \% \mathrm{CI} 0.39 \%$ to $0.80 \%$ ) (Table III, Fig. 1). With the end-point being re-revision because of acetabular loosening or infection, we found no statistical differences between the three groups. The risk of re-revision because of pain was lower in groups 2 and $3(R R=0.10$, $95 \%$ CI $0.03 \%$ to $0.30 \%$ and RR $=0.20,95 \%$ CI $0.06 \%$ to $0.65 \%$, respectively; Table III). With the end-point being dislocation or major wear of the acetabular component, we found a statistically significant reduced risk for re-revision of the acetabular components in group 3 compared with group $1(\mathrm{RR}=0.45,95 \% \mathrm{CI} 0.23 \%$ to $0.88 \mathrm{p}$-value $=$ 0.019 and $\mathrm{RR}=0.26,95 \% \mathrm{CI} 0.09 \%$ to $0.80 \% \mathrm{p}$-value $=$ 0.018 ) respectively (Table III and Fig. 2).

When dividing the primary acetabular components into two groups, those with a smooth surface and HA-coating and all the others, the results were virtually the same as in the unstratified analyses.

Categorisation of the type of first revision into five subgroups, isolated exchange of liner, revision of a well-fixed component, revision of a loose component, revision of a femoral component and a fixed acetabular component, or revision of a femoral component and a loose acetabular component produced the same results as in the main analyses. However, concomitant revision of the femoral component improved the results of complete acetabular component revisions (groups 2 and 3) compared with isolated liner exchange (group 1) (Table IV). The tendency towards better results with concomitant exchange of a femoral component was also apparent with different endpoints for re-revision (Table IV).

\section{Discussion}

In this study we found that the results of isolated acetabular liner exchange were inferior to those of complete revision of the acetabular component. Exchange of well-fixed and loose acetabular components had similar results, with a risk of a further revision being 0.56 times that of a liner exchange in both groups. As this was not a randomised study, we do not know whether there were unobserved important explanatory factors, such as bone loss or undiscovered loosening. However, the acetabular components left in situ at the time of revision (group 1) were likely to have been considered well-fixed and well-placed intra-operatively. Thus, a comparison of isolated liner exchange with revision of well-fixed components seems appropriate. In the case of acetabular component loosening, bone loss would 
Table IV. Cox-regression analyses*, for cause specific risk of re-revision, after categories of revisions

\begin{tabular}{|c|c|c|c|c|c|c|c|c|c|c|c|}
\hline \multirow{2}{*}{$\begin{array}{l}\text { Component changed } \\
\text { at revision }\end{array}$} & \multirow[b]{2}{*}{ Revisions } & \multicolumn{2}{|c|}{ All re-revisions } & \multicolumn{2}{|c|}{$\begin{array}{l}\text { Re-revision without } \\
\text { loose femur }\end{array}$} & \multicolumn{2}{|c|}{ Loose acetabulum } & \multicolumn{2}{|l|}{ Dislocation } & \multicolumn{2}{|c|}{ Major wear of cup } \\
\hline & & $\mathbf{R R}^{*}(95 \% \mathrm{Cl})$ & p-value & $R R^{*}(95 \% \mathrm{Cl})$ & p-value & $\mathrm{RR}^{*}(95 \% \mathrm{CI})$ & p-value & $\mathrm{RR}^{*}(95 \% \mathrm{Cl})$ & p-value & $\mathrm{RR}^{*}(95 \% \mathrm{Cl})$ & p-value \\
\hline Liner & 318 & $1+$ & $t$ & $1+$ & $t$ & $1+$ & $t$ & $1+$ & $t$ & $1+$ & $t$ \\
\hline A fixed cup & 300 & $\begin{array}{l}0.67 \\
(0.43 \text { to } 1.04)\end{array}$ & 0.074 & $\begin{array}{l}0.64 \\
(0.41 \text { to } 0.99)\end{array}$ & 0.0 .49 & $\begin{array}{l}0.28 \\
(0.05 \text { to } 1.69)\end{array}$ & 0.16 & $\begin{array}{l}0.87 \\
(0.40 \text { to } 1.87)\end{array}$ & 0.71 & $\begin{array}{l}0.56 \\
(0.14 \text { to } 2.26)\end{array}$ & 0.42 \\
\hline A loose cup & 716 & $\begin{array}{l}0.62 \\
(0.43 \text { to } 0.89)\end{array}$ & 0.010 & $\begin{array}{l}0.61 \\
(0.42 \text { to } 0.89)\end{array}$ & 0.010 & $\begin{array}{l}0.72 \\
(0.07 \text { to } 1.13)\end{array}$ & 0.074 & $\begin{array}{l}0.50 \\
(0.25 \text { to } 1.00)\end{array}$ & 0.052 & $\begin{array}{l}0.24 \\
(0.068 \text { to } 0.86)\end{array}$ & 0.029 \\
\hline Stem and a fixed cup & 98 & $\begin{array}{l}0.38 \\
(0.18 \text { to } 0.79)\end{array}$ & 0.010 & $\begin{array}{l}0.34 \\
(0.16 \text { to } 0.73)\end{array}$ & 0.006 & $\begin{array}{l}0.34 \\
(0.03 \text { to } 3.32)\end{array}$ & 0.35 & $\begin{array}{l}0.91 \\
(0.31 \text { to } 2.60)\end{array}$ & 0.86 & $\begin{array}{l}0.30 \\
(0.033 \text { to } 2.71)\end{array}$ & 0.28 \\
\hline Stem and a loose cup & 217 & $\begin{array}{l}0.50 \\
(0.31 \text { to } 0.80)\end{array}$ & 0.004 & $\begin{array}{l}0.39 \\
(0.23 \text { to } 0.65)\end{array}$ & $<0.001$ & $\begin{array}{l}1.49 \\
(0.40 \text { to } 5.29)\end{array}$ & 0.58 & $\begin{array}{l}0.28 \\
(0.09 \text { to } 0.87)\end{array}$ & 0.028 & $\begin{array}{l}0.29 \\
(0.063 \text { to } 1.32)\end{array}$ & 0.11 \\
\hline Total & 1649 & & $0.017 \ddagger$ & & $0.002 \ddagger$ & & & & 0.085 & & 0.211 \\
\hline
\end{tabular}

be expected to be more pronounced than with well-fixed components. Therefore, the revision procedures are often more complicated and the results less predictable and possibly inferior to those of revision undertaken in the presence of less bone loss. Surprisingly, our results were equal for revision of well-fixed and loose acetabular components, and superior to the results of isolated liner exchange, and contrast with the findings of Jiranek ${ }^{11}$ and Springer et al. ${ }^{7}$ These investigators studied the advantages of cementing a polyethylene component into a well-fixed shell. They argued that removal of a well-fixed shell can increase the loss of bone stock and hence increase morbidity and the risk of a further revision. Mitchell et $\mathrm{al}^{12}$ also found this, and discussed possible solutions to minimise bone loss at revision.

There is no consensus as to whether the well-fixed acetabular shell should be replaced or not at revision, particularly in the case of osteolysis. ${ }^{6,13}$ Few studies focus on the results of the acetabular component at revision, ${ }^{14}$ and we found none studies comparing different revision strategies for uncemented primary acetabular components.

Our findings are consistent with those of Boucher et al, ${ }^{5}$ who found a high risk for dislocation if only the liner was changed.

The three groups chosen in this study were not perfectly homogeneous. The Norwegian Arthroplasty Register provides detailed data on the patients and the procedures, the use of bone graft, reinforcement rings, meshes or cages, and the implants used at the first revision. Stratifying according to these data would result in a large number of study groups with only a small number of patients in each category, which would make comparisons impossible. Therefore, we chose the crude division of procedures into three groups and the confounders must be considered when interpreting the results. Nevertheless, we have shown that the results of liner exchange procedures were inferior to those of complete revisions of the acetabular component, whether the component was fixed or loose. This result was consistent for the subanalyses. The risk of gross bone loss at removal of ingrown acetabular components has been reported as small using modern techniques. ${ }^{12}$ Thus, the threshold for exchange of well-fixed uncemented acetabular components in the case of gross wear, bone loss, and pelvic osteolysis should probably be lowered, because if these factors are present, the risk of recurrent revisions may be increased.

The first author has been financed with the aid of EXTRA funds from the Norwegian Foundation for Health and Rehabilitation via the Norwegian Rheumatism Association.

No benefits in any form have been received or will be received from a commercial party related directly or indirectly to the subject of this article.

\section{References}

1. Lie SA, Havelin LI, Furnes ON, Engesæter LB, Vollset SE. Failure rates for 4762 revision total hip arthroplasties in the Norwegian Arthroplasty Register. J Bone Joint Surg [Br] 2004;85-B:504-9.

2. Wade FA, Rapuri VR, Parvizi J, Hozack WJ. Isolated acetabular polyethylene exchange through the anterolateral approach. J Arthroplasty 2004;19:498-500.

3. O'Brien JJ, Burnett RS, McCalden RW, et al. Isolated liner exchange in revision total hip arthroplasty: clinical results using the direct lateral surgical approach. J Arthroplasty 2004;19:414-23.

4. Della Valle CJ, Shuaipaj T, Berger RA, et al. Revision of the acetabular component without cement after total hip arthroplasty: a concise follow-up, at fifteen to nineteen years, of a previous report. J Bone Joint Surg [Am]2005;87-A:1795-800.

5. Boucher HR, Lynch C, Young AM, Engh CA Jr, Engh C Sr. Dislocation after polyethylene liner exchange in total hip arthroplasty. J Arthroplasty 2003;18:654-7.

6. Beaule PE, Ebramzadeh E, LeDuff M, Prasad R, Amstutz HC. Cementing a liner into a stable cementless acetabular shell: the double-socket technique. J Bone Joint Surg [Am] 2004;86-A:929-34.

7. Springer BD, Hanssen AD, Lewallen DG. Cementation of an acetabular liner into a well-fixed acetabular shell during revision total hip arthroplasty. J Arthroplasty 2003;18(Suppl 1):126-30.

8. Espehaug B, Furnes 0, Haveline LI, et al. Registration completeness in the Norwegian Arthroplasty Register. Acta Orthop 2006;77:49-56.

9. Havelin LI. The Norwegian Joint Registry. Bull Hosp Jt Dis 1999;58:139-47.

10. Havelin LI, Espehaug B, Engesæter LB. The performance of two hydroxyapatitecoated acetabular cups compared with Charnley cups: from the Norwegian Arthroplasty Register. J Bone Joint Surg [Br] 2002;84-B:839-45.

11. Jiranek WA. Acetabular liner fixation by cement. Clin Orthop 2003;417:217-23.

12. Mitchell PA, Masri BA, Garbuz DS, et al. Removal of well-fixed, cementless, acetabular components in revision hip arthroplasty. J Bone Joint Surg [Br] 2003;85B:949-52.

13. Berry DJ. Liner and femoral head exchange for osteolysis. Orthopedics 2003;26:93940.

14. Schreurs BW, Bolder SB, Gardeniers JW, et al. Acetabular revision with impacted morsellised cancellous bone grafting and a cemented cup: a 15- to 20-year follow-up. J Bone Joint Surg [Br] 2004;86-B:492-7. 